\title{
Design rainfall estimation using probabilistic approach for Adilabad district of Telangana
}

\author{
A.M. WAGHAYE, V. SIDDENKI, NIDHI KUMARI AND V.K. INGLE
}

\begin{abstract}
This paper presents the estimation of design rainfall of Adilabad district at different probability levels. The 30 years (1972-2001) monthly rainfall data of Adilabad district were analyzed by EasyFit software to identify the best fit probability distribution. Chisquare test is used as a goodness of fit criteria. It was found that general extreme value, Gamma distribution and Gumbel max were best fitted to monsoon (June-Sept.), post-monsoon (March-May) and pre-monsoon (Oct.-Feb.) season, respectively. The data was then processed to identify the design rainfall received in a monsoon (June-Sept.), pre-monsoon (March-May) and post-monsoon (Oct.-Feb.) season. Analysis of 30 years (1972-2001) rainfall data in the study area showed an average annual rainfall of Adilabad district is $1024.8 \mathrm{~mm}$. According to Indian Meteorological Department (IMD), the meteorological drought year is defined as a year in which less than 75 per cent of the average annual rainfall is received. Based upon these criteria, the years 1972, 1974, 1984 can be characterized as drought years. After fitting the probability distribution, the frequency factor method was used to estimate the design rainfall at different probability level which can be use to design catchment to cultivated area ratio of micro-catchment water harvesting system.
\end{abstract}

KEY WORDS : Chi-Square test, Design rainfall, EasyFit, Gamma, General extreme value, Gumbel, Probability distribution

How to cite this Article : Waghaye, A.M., Siddenki, V., Kumari, Nidhi and Ingle, V.K. (2015). Design rainfall estimation using probabilistic approach for Adilabad district of Telangana. Engg. \& Tech. in India, 6 (1) : 1-11. 